\title{
Metoprolol-induced Total Body Erythroderma
}

\author{
Jeffrey B. Doyon, MD, $P h D^{7}$, Kristina J. Liu, $M D^{2}$, and Rebecca A. Berman, $M D^{7}$ \\ 'Department of Medicine, Brigham and Women's Hospital, Boston, MA, USA; ${ }^{2}$ Department of Dermatology, Brigham and Women's Hospital, \\ Boston, MA, USA.
}

KEY WORDS: psoriasis; erythroderma; drug reaction; beta-blocker. J Gen Intern Med 32(2):221-2

DOI: $10.1007 / \mathrm{s} 11606-016-3900-2$

(C) Society of General Internal Medicine 2016
She had thick, micaceous scale covering her entire scalp, with sparse eyebrows and eyelashes.

The differential diagnosis for erythroderma includes psoriasis, atopic dermatitis, drug eruptions, hematologic malignancies, and cutaneous T-cell lymphomas. ${ }^{1}$ A punch biopsy showed psoriasiform dermatitis with abundant eosinophils, consistent with a drug-induced hypersensitivity reaction superimposed on a psoriatic diathesis. Medications, including tetracyclines, lithium, and beta-blockers, can directly trigger a psoriasis flare. $^{2}$ Alternatively, medications that cause a hypersensitivity reaction may trigger a psoriasis flare through the
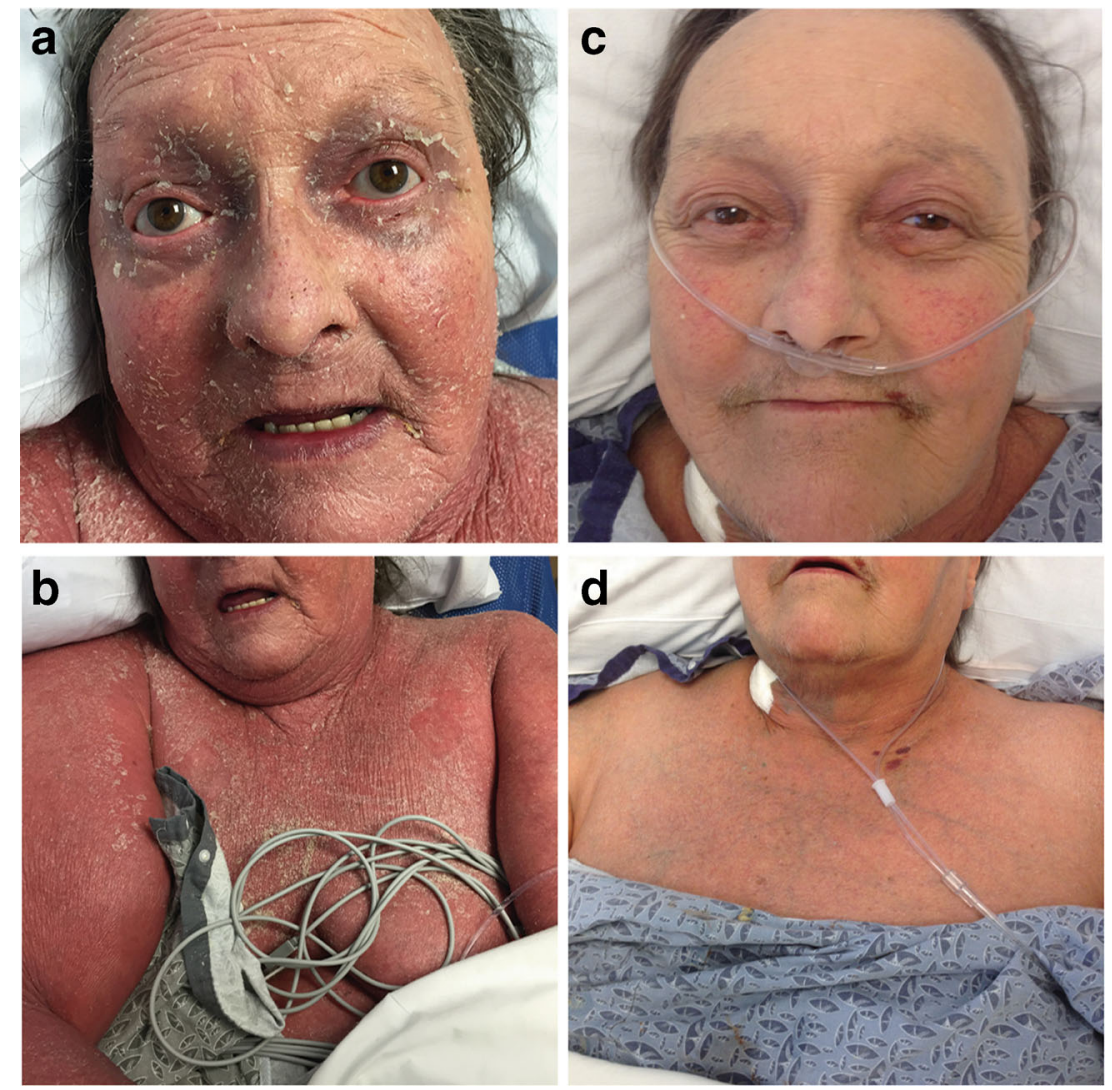

Figure 1 On presentation, the patient had total body erythroderma and generalized scaling (a and b). After treatment with systemic cyclosporine and topical steroids for 4 weeks, the patient had a significant improvement in the micaceous scale on her scalp (c), and the total body erythroderma almost completely resolved (c and d) 
Koebner phenomenon. ${ }^{3}$ The latter mechanism was implicated in this case, with metoprolol as the offending agent.

This patient's metoprolol was discontinued, and she was treated with oral cyclosporine with significant improvement of her skin findings (Fig. 1c-d). This case highlights how betablockers, a common class of medications, can cause a dramatic flare of a patient's psoriasis. These medications should be discontinued if possible when there is a concern for a druginduced psoriasis flare.

Corresponding Author: Jeffrey B. Doyon, $M D$, PhD; Department of MedicineBrigham and Women's Hospital, Boston, MA, USA (e-mail:jbdoyon@partners.org).

\section{Compliance with Ethical Standards:}

Conflict of Interest: The authors declare that they do not have a conflict of interest.

\section{REFERENCES}

1. Okoduwa C, Lambert WC, Schwartz RA, Kubeyinje E, Eitokpah A, Sinha S, Chen W. Erythroderma: review of potentially life-threatening dermatosis. Indian J Dermatol. 2009;54:1-6.

2. Rongioletti F, Fiorucci C, Parodi A. Psoriasis induced or aggravated by drugs. J Rheumatol. 2009;83:59-61.

3. Ahad T, Agius E. The Koebner phenomenon. Br J Hosp Med. 2015;76:C170-C172. 